\title{
Influence of Semi-Solid Isothermal Heat Treatment on Microstructure and Mechanical Properties of Ductile Cast Iron
}

\author{
Mohamed Ramadan ${ }^{1,2}$, Naglaa Fathy ${ }^{3 *}$ \\ ${ }^{1}$ College of Engineering, University of Hail, Hail, KSA \\ ${ }^{2}$ Central Metallurgical R\& D Institute, Helwan, Egypt \\ ${ }^{3}$ Physics Department, College of Science, University of Hail, Hail, KSA \\ Email: "naglaaf2002@yahoo.com
}

Received November 2, 2013; revised December 3, 2013; accepted December 13, 2013

Copyright (C 2014 Mohamed Ramadan, Naglaa Fathy. This is an open access article distributed under the Creative Commons Attribution License, which permits unrestricted use, distribution, and reproduction in any medium, provided the original work is properly cited. In accordance of the Creative Commons Attribution License all Copyrights (C) 2014 are reserved for SCIRP and the owner of the intellectual property Mohamed Ramadan, Naglaa Fathy. All Copyright (C 2014 are guarded by law and by SCIRP as a guardian.

\begin{abstract}
In this research, the effect of semi-solid isothermal heat treatment on microstructure, hardness and impact toughness of ductile iron (DI) is studied. Heat-treated air-cooled ductile iron shows spheroid graphite, cementite and fine pearlite matrix structure. At the early stages of heating time (up to 20 min), the DIs show significant decrease in amounts of graphite and significant increase in amounts of cementite. By increasing heating time, above $20 \mathrm{~min}$, the DIs show slightly decrease in amounts of graphite and slightly increase in amounts of cementite. Hardness values increase by increasing heating time. Meanwhile, the impact toughness decrease with increasing heating time. The optimum heating treatment condition for reasonable structure and mechanical properties could be achieved at the temperature of $1165^{\circ} \mathrm{C}$ for the heating time range of 10 to $15 \mathrm{~min}$.
\end{abstract}

\section{KEYWORDS}

\section{Ductile Iron; Fittings and Accessories; Heat Treatment; Microstructure; Semi-Solid}

\section{Introduction}

Ductile irons are very unique engineering materials. They possess good castability, damping capacity and mechanical properties and fair machinability. Owing to these advantages, ductile irons have been used in many structural applications. Steering knuckles, hypoid rear axle gears, camshafts, crankshafts and disk-brake calipers are important examples of ductile iron used in vehicles [1-3]. Waterworks pipe fittings and accessories also are considered to be one of the important applications of DI. Heat treating of DI is also another method to produce a family of materials offering a wide range of properties obtained through matrix microstructure control [4]. Although there are currently a plenty of new and advanced materials, cast irons are still the most used casting alloy for its considerable reduction in their cost of production. Their popularity stems from an ability to cast

\footnotetext{
*Corresponding author.
}

complex shapes at relatively low cost and the wide range of properties that can be achieved by careful control over composition and cooling rate $[5,6]$.

Ductile cast irons are characterized by a very interesting combination of castability and mechanical properties (as tensile strength, toughness, wear and crack propagation resistance). This combination is strongly affected by the metal matrix microstructure, by the impurities presence and by the graphite particles morphology. Specifically, the high toughness values and good crack propagation resistance are mainly due to the peculiar graphite elements shape, which is approximately spheroidal. Morphology of graphite particles is a critical parameter and, as a consequence, its characterization and control are extremely important [7]. At present, the methods of obtaining semi-solid materials with non-dendritic microstructure include mechanical stirring (MS), electromagnetic stirring (ES), strain-induced melt activation (SIMA), spray deposition (SD), liquidus cast and semi-solid iso- 
thermal heat treatment $[8,9]$. Among these methods, the semi-solid isothermal heat treatment is a new way being found in the 1990s, which omits the special procedure to fabricate the semi-solid materials but fulfils the semisolid non-dendritic microstructure during heating.

This research is aimed to study the effect of isothermal heat treatment for ductile cast iron in semi-solid state on structure, especially graphite morphology and matrix structure, and related mechanical properties. Wide range of application is the main goal for this research to obtain high performance DI iron through control of their microstructure, especially graphite morphology by semi-solid isothermal heat treatment.

\section{Experimental Work}

The alloy was melted in a $350 \mathrm{~kg}$ capacity medium frequency induction furnace with a silica lining and treated with Fe-Si-Mg alloy using a sandwich method. Ductile cast iron containing spheroidal graphite morphologies were cast into $12.5 \mathrm{~mm}$ Y blocks made from green sand moulds. A treatment alloy containing about $9 \% \mathrm{Mg}$ and $0.7 \%$ Ce was used in order to obtain certain amounts of residual $\mathrm{Mg}$, and $\mathrm{Ce}$ in the final cast irons (see Table 1). All the Y block specimens were poured from the same base melt to keep the carbon equivalent and alloying elements constant.

The differential scanning calorimetric analysis (DSC) for the studied gray cast iron was conducted showing that solidus temperature of $1158^{\circ} \mathrm{C}$. Specimens of approximate dimensions $15 \times 15 \times 15 \mathrm{~mm}$ were cut from both side of the $\mathrm{Y}$ blocks for isothermal heat treatment as well as microstructure examination and graphite morphology measurements. All of the test specimens were sampled from the same position in the Y blocks and the top sections of the blocks were rejected in order to avoid variations in graphite morphology and porosity. All specimens were heated to $1165^{\circ} \mathrm{C}$ hold for $10,15,20,25$ and 30 mins, respectively in an electrically heated resistance furnace with heating rate of $10^{\circ} \mathrm{C} \cdot \mathrm{min}^{-1}$. After the semisolid heat treatment, the samples were taken out imme-

Table 1. Chemical analysis of DI samples, wt. \%.

\begin{tabular}{cccc}
\hline Element & wt. \% & Element & wt. \% \\
\hline $\mathrm{C}$ & 3.39 & $\mathrm{Cr}$ & 0.03 \\
$\mathrm{Si}$ & 2.58 & $\mathrm{Ni}$ & 0.02 \\
$\mathrm{Mn}$ & 0.31 & $\mathrm{Al}$ & 0.01 \\
$\mathrm{P}$ & 0.02 & $\mathrm{Mg}$ & 0.05 \\
$\mathrm{~S}$ & 0.01 & C.E. $^{\mathrm{a}}$ & 4.26 \\
$\mathrm{Cu}$ & 0.30 & $\mathrm{~T}_{\mathrm{s}}\left({ }^{0} \mathrm{C}\right)^{\mathrm{b}}$ & 1158 \\
\hline
\end{tabular}

${ }^{\mathrm{a} C . E .: ~ C a r b o n ~ E q u i v a l e n t ~(=~ \% ~ C ~+~ 1 / 3 ~(\% ~ S i ~+~ \% ~ P)), ~}{ }^{\mathrm{b}}$ Solidus temperature. diately for air cooling.

Specimens in either as cast or heat treated condition were grinded, polished, etched with $4 \%$ nital and examined metallographically using an optical microscope and photomicrographs were taken. Percent area of graphite, pearlite, cementite and mean graphite length were automatically calculated by Scentis image analyzer software. Rockwell hardness test were also performed using 1/16 inch diameter ball and $60 \mathrm{~kg}$ load (with errors 2\%). To investigate the impact toughness, the impact tests were carried out using pendulum impact tester $300 \mathrm{Nm}$ machine for un-notched samples of dimensions $10 * 10 *$ $55 \mathrm{~mm}$.

\section{Results and Discussion}

The effect of reheating temperatures on the microstructures of DI at the optimum reheating time has been reported in the literature [10] where, optimum reheating condition of spherical and the rounded primary solid was attained at the temperature of $1165^{\circ} \mathrm{C}$ for $15 \mathrm{~min}$. However, the previous literature [10] did not include any discussion on the effect of semi-solid isothermal heat treatment on the morphology of the graphite and matrix structure changes and its affect on mechanical properties of DI. In the present study graphite morphology, percent of graphite and percent of cementite in DI structure significantly changed due to isothermal heating at $1165^{\circ} \mathrm{C}$ for heating time range from 10 to $20 \mathrm{~min}$ and slight changed for heating time above $20 \mathrm{~min}$ as shown in Figures 1-3.

The as cast DI shows spheroid graphite dispersed ferritic pearlitic matrix (see Table 2), on the other hand, isothermally heat treated air cooled DI shows graphite particle, cementite and fine pearlite matrix structure, as shown in Figure 1.

At the early stages of heating time (up to $20 \mathrm{~min}$ ), the DIs show significant decrease in amounts of graphite and significant increase in amounts of cementite. By increasing heating time, above $20 \mathrm{~min}$, the gray irons show slightly decrease in amounts of graphite and slightly

Table 2. Quantitative measurement of structural features of as cast DI.

\begin{tabular}{cc}
\hline Graphite \% & 9 \\
Ferrite \% & 35.55 \\
Pearlite \% & 55.45 \\
Graphite grain size, $\mu \mathrm{m}$ & 35 \\
Graphite sphericity & 0.92 \\
Hardness, HRC & 20.25 \\
Impact toughness, J & 14.8 \\
\hline
\end{tabular}



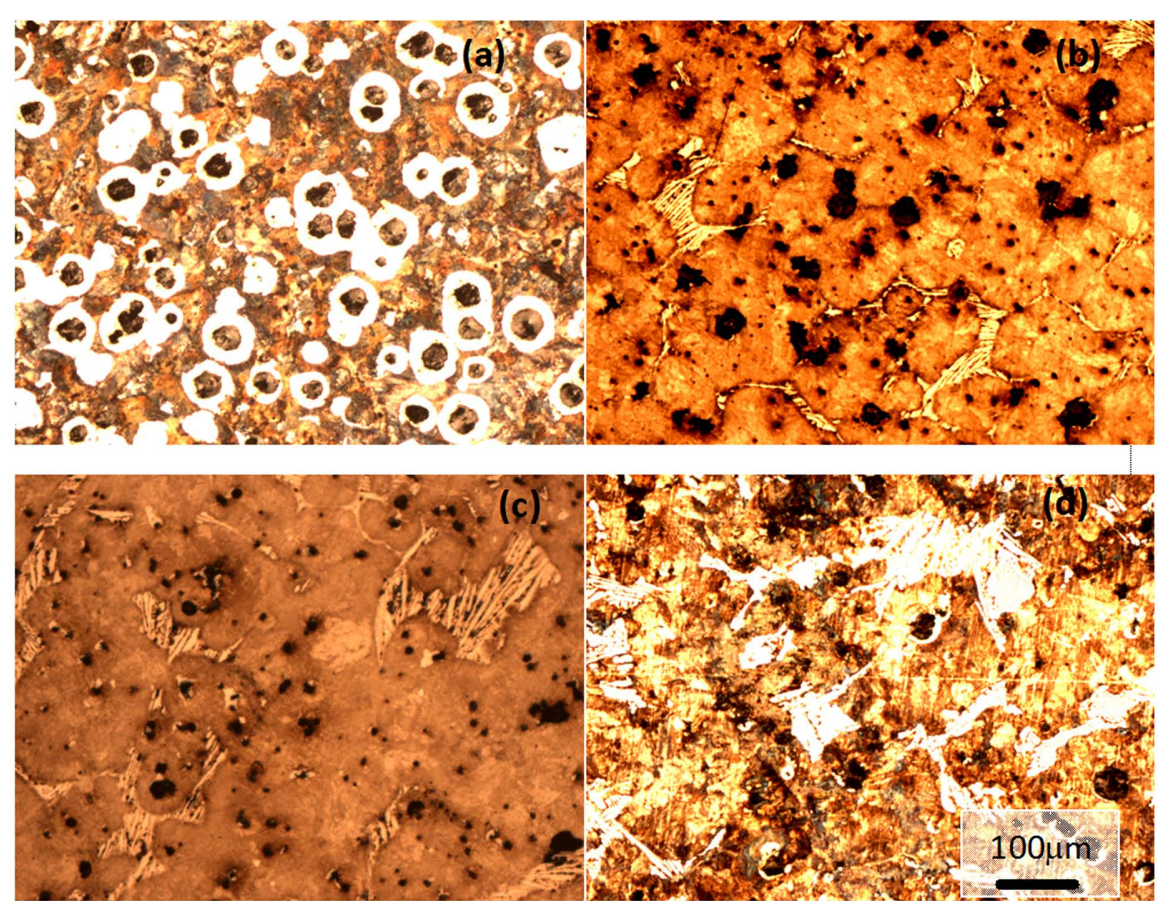

Figure 1. Microstructure of ductile cast iron (a) as cast, and isothermally heat treated at $1165^{\circ}$ for (b) $10 \mathrm{~min}$, (c) $20 \mathrm{~min}$, (d) 30 min.

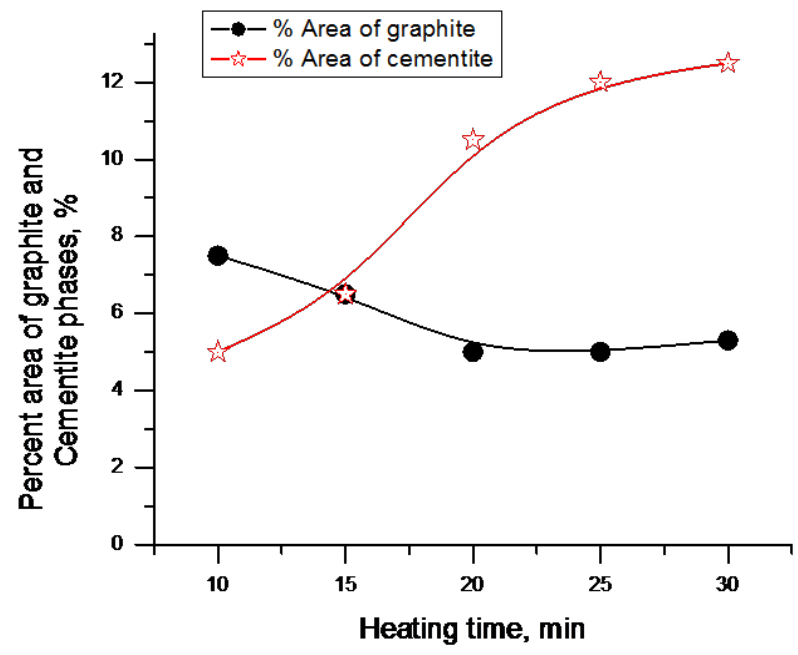

Figure 2. Effect of heating time on percent of graphite and cementite of DI heat treated at $1165^{\circ} \mathrm{C}$.

increase in amounts of cementite. Pervious study [10] dealing with the microstructure of reheated semisolid cast ductile iron for different holding time, indicated that, at the holding time of $5 \mathrm{~min}$ at $1165^{\circ} \mathrm{C}$, the liquid is formed only at the corner of the grain boundaries because of their low melting points. At the reheating time of 10 min, the most grain boundaries become liquid but the primary solid nodules remain unchanged. At the holding time of $15 \mathrm{~min}$, the shape of the primary solids gradually changes to spherical and the rounded islands are created. With increasing holding time to $20 \mathrm{~min}$ and more, liquid

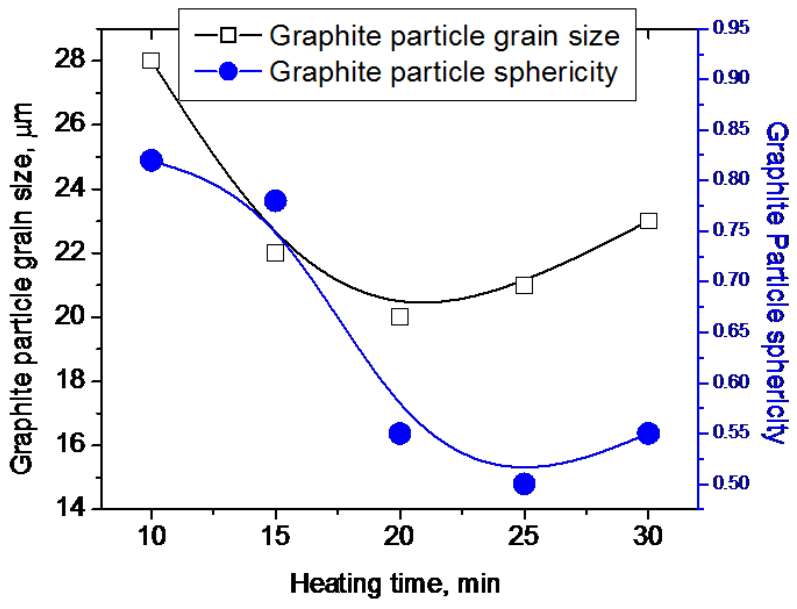

Figure 3. Graphite particle grain size and sphericity as a function of heating time of DI heat treated at $1165^{\circ} \mathrm{C}$.

fraction and solid globularity change slightly.

Pervious study [10] concentrated only on grain size and primary grain morphology changed by heating time and has not been mentioned for such effects on graphite morphology and matrix structure.

The present study and pervious one [10] are in a good agreement that increasing heating time will increase significantly the fraction of liquid to certain heating time value and above this value the fraction of liquid slightly increases. This concept, explain the behavior shown in Figure 2, the change of graphite and cementite values are strongly concerned by carbon diffusion at high tem- 
perature $\left(1165^{\circ} \mathrm{C}\right)$. Up to 20 min heating time and related amount of liquid fraction lead to slightly increase the carbon diffusions from high carbon concentrations (spheroid graphite) zones to the to the matrix structure, meanwhile, above heat time of 20 min the increases of carbon diffusion decreases the percent of carbon in cementite due to the action of air cooling as well.

It is clear that graphite morphology affected generally by the heating time. Carbon diffusion is the main reason that led to graphite grain size decreases by heating time. At the early stages of heating time (up to $20 \mathrm{~min}$ ), increasing the amount of liquid by increasing heating time leads to the higher diffusion rate of carbon in iron/graphite interface areas that are relatively lower in carbon content result in decreasing of graphite grain size. The irregular area of iron/graphite interface areas and the irregular low carbon area around graphite result in different diffusion rates of carbon from iron/graphite interface areas to the surrounding matrix. The different diffusion rates of carbon decrease the graphite particle sphericity by increasing heating time up to $20 \mathrm{~min}$ (see Figure 3 ).

Although the pervious study [10] indicated that increasing heating time led to increasing primary particle globularity, it is clear that in current study that graphite particle sphericity and graphite particle grain size significantly decreases up to $20 \mathrm{~min}$ heating time due to the higher diffusion rate of carbon. Above 20 min heating time both of graphite particle sphericity and graphite particle grain size slightly increase due to lower diffusion rate of carbon and particle agglomerations.

Figure 4 shows a clear interface martensitic matrix layer on the surface of all semi-solid isothermal heat treated DI specimen. The higher cooling rate on the surface of specimen is considered to be the reason of this martensitic matrix layer formation.

The thickness of this martensitic layer significantly increases with increasing the isothermal heating time up to heating time of $20 \mathrm{~min}$ (see Figure 5). This increment could be related to the increasing of liquid fraction in liquid-solid mixture by increasing heating time up to 20 min heating. Meanwhile, above 20 min heating, the martensitic layer show constant measurement thickness value due to the liquid saturation in liquid-solid mixture at $1165^{\circ} \mathrm{C}$.

Figure 6 shows values of hardness and impact toughness as a function of heating time of semi-solid isothermally heat treated DI at $1165^{\circ} \mathrm{C}$. It is clear that hardness increases with increasing heating time as shown in Figure 6(a).

Increasing of hardness could be explained by the increasing of percent of cementite phase by heating time. On the other hand, the value of impact toughness decreases by increasing heating time as shown in Figure 6(b). The decreasing of graphite sphericity and increasing the percent of cementite phase are believed to be the main reason of decreasing the impact toughness. The graphite morphology plays an important rule and the more the graphite shape deviates from the ideal spherical shape the lower the ductility and strength.

Damaging micromechanisms are strongly affected by microstructure; both graphite elements and metal matrix are involved. The difference in strength properties for different graphite nodularity levels seems to be princi-
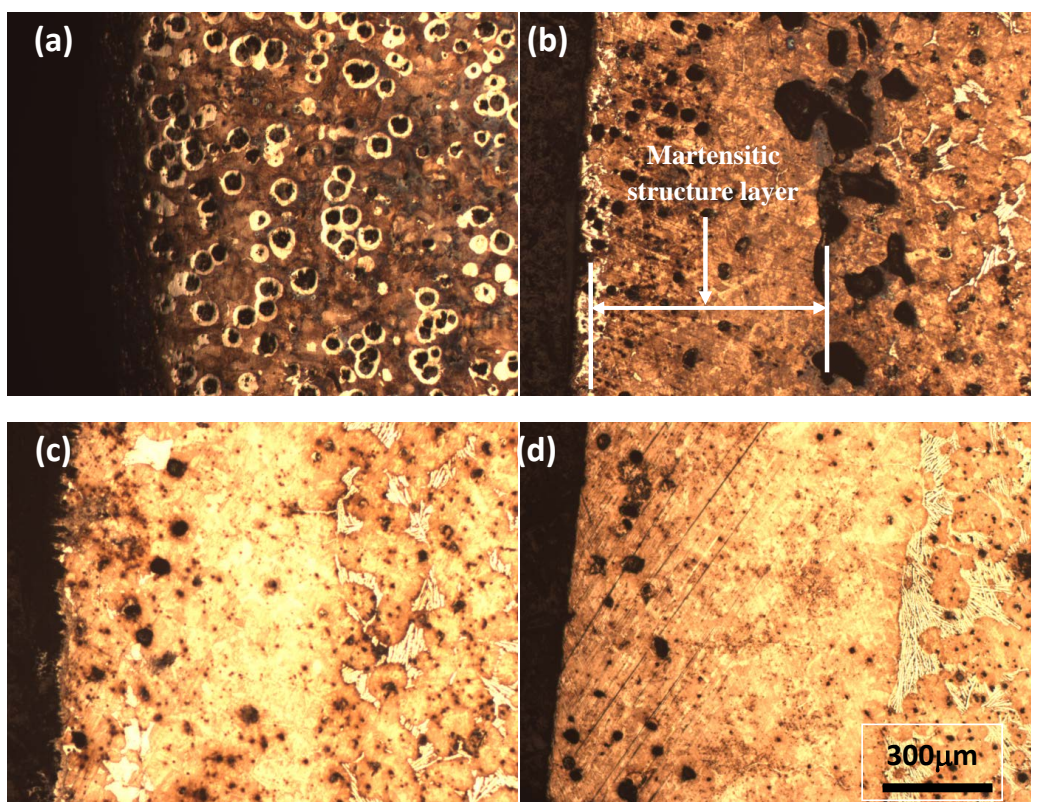

Figure 4. Surface microstructure of as-cast (a) and Surface martensitic structure layer for semi-solid isothermal heat treated DI for heating time of (b) $10 \mathrm{~min}$, (c) $15 \mathrm{~min}$ and c) $30 \mathrm{~min}$. 


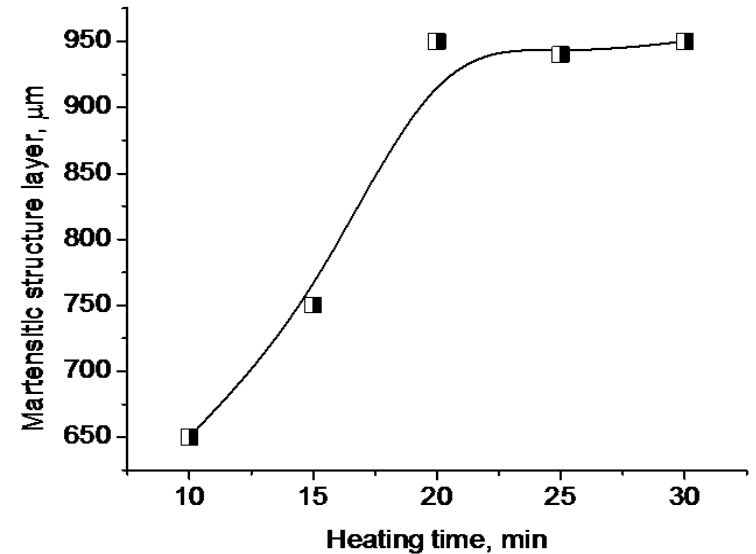

Figure 5. Martensitic structure layer as a function of heating time.
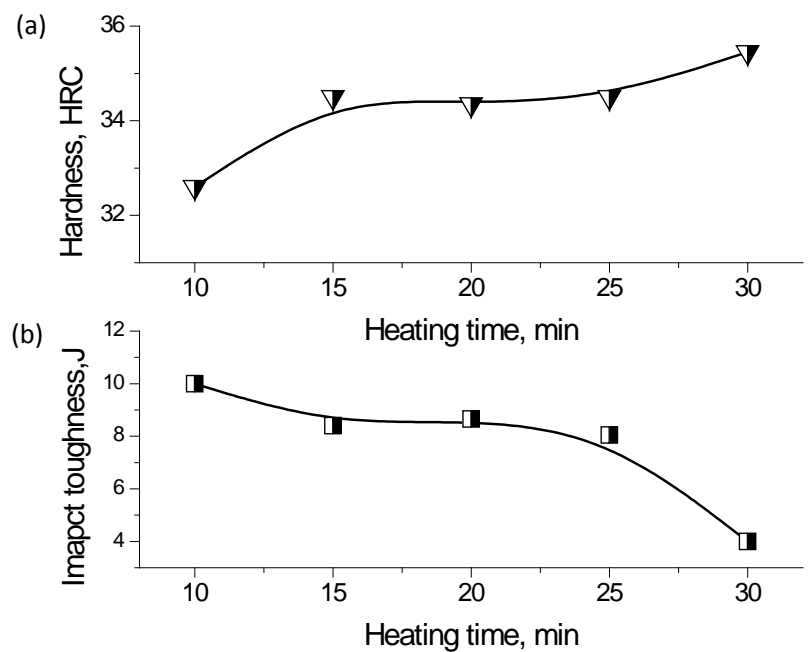

Figure 6. Hardness and impact toughness as a function of heating time of semi-solid isothermally heat treated DI at $1165^{\circ} \mathrm{C}$.

pally due to the easier crack propagation with lower degree of graphite nodularity [11,12].

From the current results and to optimize the isothermal heat treatment of ductile iron and taking the amount of cementite to be minimum in matrix structure (to keep the mechanical and physical properties at a reasonable range), the range of 10 to $15 \mathrm{~min}$ heating time at $1165^{\circ} \mathrm{C}$ should be attended.

\section{Conclusions}

Investigations carried out to study the influence of semisolid isothermal heat treatment on microstructure of ductile iron and mechanical properties lead to the following conclusions:

1) Heat treated air cooled ductile iron shows spheroid graphite, cementite and fine pearlite matrix structure.

2) At the early stages of heating time (up to $20 \mathrm{~min}$ ), the DIs show significant decrease in amounts of graphite and significant increase in amounts of cementite. By increasing heating time, above 20 min, the DIs show slightly decrease in amounts of graphite and slightly increase in amounts of cementite.

3) Above heat time of 20 min the increase of carbon diffusion decreases the percent of carbon in graphite spheroid during holding time and increases the percent of cementite due to the action of air cooling as well.

4) Formation of martensetic structure layer for heat treated DI due to higher cooling rate on the surface of specimen.

5) Hardness values increase by increasing heating time due to increasing of percent of cementite phase.

6) Impact toughness decreases with increasing heating time due to decreasing of graphite sphericity and increasing the percent of cementite phase.

7) The optimum heating treatment condition for reasonable structure and mechanical properties could be achieved at the temperature of $1165^{\circ} \mathrm{C}$ for the heating time range of 10 to 15 mins.

\section{Acknowledgements}

The authors gratefully acknowledge the support of their research program by Staff of Foundry Technology Lab of Central Metallurgical R\&D Institute and Bin Laden Research Chair on Quality and Productivity Improvement in the Construction Industry. The authors would like to thank Prof. Dr. K. S. Abdel Halim and Dr. K. M. hafez of College of Engineering, University of Hail for the useful discussion and technical support.

\section{REFERENCES}

[1] P. Shanmugam, P. P. Rao, K. R. Udupa and N. Venkataraman, "Effect of Microstructure on the Fatigue Strength of an Austempered Ductile Iron,” Journal of Materials Science, Vol. 29, No. 18, 1994, pp. 4933-4940.

[2] S. C. Lin, T. S. Lui, L. H. Chen and J. M. Song, "Effect of Pearlite on the Vibration-Fracture Behavior of Spheroidal Graphite Cast Irons under Resonant Conditions,” Metallurgical and Materials Transactions A, Vol. 33, No. 8, 2002, pp. 2623-2634.

[3] G. Toktaş, M. Tayanç and A. Toktaş, "Effect of Matrix Structure on the Impact Properties of an Alloyed Ductile Iron,” Materials Characterization, Vol. 57, No. 4-5, 2006, pp. 290-299.

[4] M. Hafiz, "Mechanical Properties of SG-Iron with Different Matrix Structure,” Journal of Materials Science, Vol. 36, No. 5, 2001, pp. 1293-1300.

[5] R. Elliott, “Cast Iron Technology,” Butterworths, London, 1988.

[6] B. Leube and L. Arnberg, "Modeling of Iron Solidification Microstructure for Prediction of Mechanical Properties,” International Journal of Cast Metals Research, Vol. 
11, No. 6, 1999, pp. 507-514.

[7] A. De Santis, O. Di Bartolomeo, D. Iacoviello and F. Iacoviello, "Quantitative Shape Evaluation of Graphite Particles in Ductile Iron,” Journal of Materials Processing Technology, Vol. 196, No. 1, 2008, pp. 292-302.

[8] T. J. Chen, Y. Ma, Y. Hao, S. Lu, G. J. Xu and J. Sun, "Structural Evolution of ZA27 Alloy during Semi-Solid Isothermal Heat Treatment," Transactions of Nonferrous Metals Society of China, Vol. 11, No. 1, 2001, pp. 98102.

[9] J. M. Kim, K. T. Kim and W. J. Jung, "Effects of Isothermal Heating Procedure and Strontium Addition on Semisolid Forming of AZ91 Magnesium Alloy," Materials Science and Technology, Vol. 18, No. 6, 2002, pp.
698-701.

[10] B. Abbasi-Khazaei and S. Ghaderi, "A Novel Process in Semi-Solid Metal Casting,” Journal of Materials Science \& Technology, Vol. 28, No. 10, 2012, pp. 946-950.

[11] M. Ramadan, A. A. Nofal, I. Elmahalawi and R. AbdelKarim, "Influence of Graphite Nodularity on Microstructure and Processing, Window of $1.5 \% \mathrm{Ni}-0.3 \%$ Mo Austempered Cast Iron,” Materials Science and Engineering A, Vol. 435-436, 2006, pp. 564-572. http://dx.doi.org/10.1016/j.msea.2006.07.108

[12] F. Iacoviello, O. Bartolomeo, V. Di Cocco and V. Piacente, "Damaging Micromechanisms in Ferritic-Pearlitic Ductile Cast Irons,” Materials Science and Engineering A, Vol. 478, No. s1-2, 2008, pp. 181-186. 